\title{
Chronic Pulmonary Aspergillosis: Notes for a Clinician in a Resource-Limited Setting Where There Is No Mycologist
}

\author{
Felix Bongomin ${ }^{1, * \mathbb{C}}$, Lucy Grace Asio ${ }^{1}$, Joseph Baruch Baluku ${ }^{2} \mathbb{D}$, Richard Kwizera ${ }^{3} \mathbb{C}$ \\ and David W. Denning 4,5 (i) \\ 1 Department of Medical Microbiology \& Immunology, Faculty of Medicine, Gulu University, \\ Gulu P.O. Box 166, Uganda; asiolucia@yahoo.com \\ 2 Division of Pulmonology, Mulago National Referral Hospital, Kampala P.O. Box 7051, Uganda; \\ bbjoe18@gmail.com \\ 3 Translational Research Laboratory, Infectious Diseases Institute, College of Health Sciences, Makerere \\ University, Kampala P.O. Box 22418, Uganda; kwizerarichard@ymail.com \\ 4 The National Aspergillosis Centre, Wythenshawe Hospital, Manchester University NHS Foundation Trust, \\ Manchester M23 9LT, UK; david.denning@manchester.ac.uk \\ 5 Division of Infection, Immunity and Respiratory Medicine, School of Biological Sciences, Faculty of Biology, \\ Medicine and Health, The University of Manchester, Manchester M13 9PL, UK \\ * Correspondence: felix.ayoli9@gmail.com; Tel.: +256-78452-3395
}

Received: 30 April 2020; Accepted: 31 May 2020; Published: 2 June 2020

\begin{abstract}
Chronic pulmonary aspergillosis (CPA) is a spectrum of several progressive disease manifestations caused by Aspergillus species in patients with underlying structural lung diseases. Duration of symptoms longer than three months distinguishes CPA from acute and subacute invasive pulmonary aspergillosis. CPA affects over 3 million individuals worldwide. Its diagnostic approach requires a thorough Clinical, Radiological, Immunological and Mycological (CRIM) assessment. The diagnosis of CPA requires (1) demonstration of one or more cavities with or without a fungal ball present or nodules on chest imaging, (2) direct evidence of Aspergillus infection or an immunological response to Aspergillus species and (3) exclusion of alternative diagnoses, although CPA and mycobacterial disease can be synchronous. Aspergillus antibody is elevated in over $90 \%$ of patients and is the cornerstone for CPA diagnosis. Long-term oral antifungal therapy improves quality of life, arrests haemoptysis and prevents disease progression. Itraconazole and voriconazole are alternative first-line agents; voriconazole is preferred for patients with contra-indications to itraconazole and in those with severe disease (including large aspergilloma). In patients co-infected with tuberculosis (TB), it is not possible to treat TB with rifampicin and concurrently administer azoles, because of profound drug interactions. In those with pan-azole resistance or intolerance or progressive disease while on oral triazoles, short-term courses of intravenous liposomal amphotericin B or micafungin is used. Surgery benefits patients with well-circumscribed simple aspergillomas and should be offered earlier in low-resource settings.
\end{abstract}

Keywords: chronic pulmonary aspergillosis; mycoses; lung disease; resource-limited setting; epidemiology; chest X-ray; Aspergillus IgG

\section{Introduction}

Aspergillus is one of the oldest known genera of fungi first described by a Roman Catholic clergyman and biologist Pier Antonio Micheli in 1729 [1]. To date, over 330 species of Aspergillus have been described [2]. Of these, approximately 50 species are recognised to be pathogenic to humans, 
and the five most clinically relevant include Aspergillus fumigatus, A. flavus, A. niger, A. terreus, and A. nidulans, in order of frequency [3,4]. Aspergillosis is a generic term used to describe almost all diseases caused by the opportunistic fungi of the genus Aspergillus [5]. Aspergillosis is acquired by way of inhalation or traumatic inoculation of Aspergillus spores from dead and decaying organic matter in the environment [6,7]. Human-to-human or animal-to-human transmissions have not been reported [5].

Aspergillosis syndromes are immensely diverse. These syndromes can be also quite fluid if the individual's immune status changes. While the immune status dictates what form of aspergillosis the patient is at risk of, it also dictates whether or not they are likely to get aspergillosis at all. The following syndromes have been described: (1) acute invasive sinopulmonary disease occurring in severely immuncompromised patients such as those with haematological malignancies, post-transplantation immunosuppression, graft-versus-host disease (GvHD), chronic granulomatous disease, intensive care, decompensated liver cirrhosis and HIV/AIDS; (2) sub-acute invasive and chronic aspergillosis, observed in patients with poorly controlled diabetes, alcohol excess and prolonged systemic corticosteroid therapy (for sub-acute invasive), or those with underlying structural diseases of the lungs and sinuses with impaired physiological or anatomic barriers of innate immunity (for chronic); (3) allergic rhinosinusitis and hypersensitivity lung diseases, observed in patients with atopy, asthma or cystic fibrosis, and (4) mucocutaneous and subcutaneous forms of aspergillosis such as onychomycosis, keratitis and Madura foot which follow traumatic inoculation of the spores directly into the affected tissues [8,9]. Since Aspergillus species are ubiquitous in the environment and humans inhale Aspergillus spores on a daily basis, sinopulmonary diseases are the most common manifestations of aspergillosis [10,11].

Three major Aspergillus-related bronchopulmonary syndromes account for the major causes of morbidity and mortality due to aspergillosis globally [12-14]: (1) allergic bronchopulmonary aspergillosis (ABPA), which is an eosinophilic hypersensitivity lung disease classically seen in patients with worsening symptoms of asthma, chronic obstructive pulmonary disease (COPD) and cystic fibrosis; (2) invasive pulmonary aspergillosis (IPA), which is an acute life-threatening disease mainly seen in patients with severe immunosuppression such as those on corticosteroids, and (3) chronic pulmonary aspergillosis (CPA), which is a progressive debilitating parenchymal lung disease manifesting in patients with pre-existent cavitary, structural lung disease or those with subtle immune defects. In addition, a small group of patients, especially those with moderate immunosuppression (poorly controlled diabetes, alcohol excess and liver cirrhosis) develop sub-acute invasive aspergillosis (SAIA) - a less active invasive disease that progresses over days to weeks ( $<3$ months) with a propensity of transforming to IPA or CPA (Figure 1).

This narrative review highlights some of the essential information required by a non-specialist mycologist/clinician in a resource-limited setting: this clinician will occasionally encounter patients with CPA in their practice and will need this information to recognise patients at risk and diagnose and appropriately manage them. 


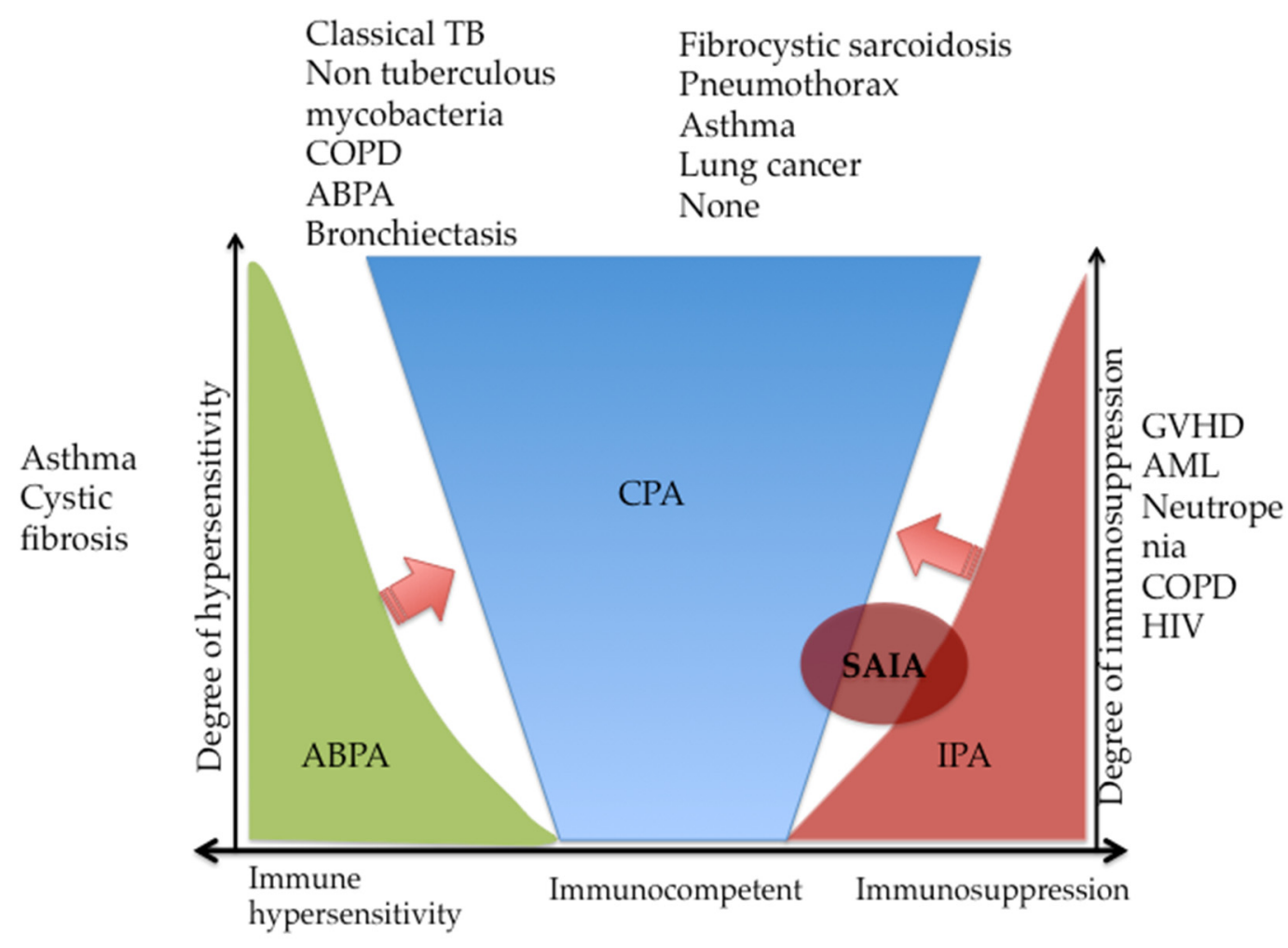

Figure 1. Spectrum of pulmonary aspergillosis based on the host-pathogen damage framework. ABPA, allergic bronchopulmonary aspergillosis; CPA, chronic pulmonary aspergillosis; IPA, invasive pulmonary aspergillosis; SAIA, subacute invasive pulmonary aspergillosis; GVHD, graft-versus-host disease; AML, acute myeloid leukaemia; COPD, chronic obstructive pulmonary disease; HIV, human immunodeficiency virus; TB, tuberculosis. ABPA and IPA can progress to CPA (arrows).

\section{Definition and Pathogenesis}

CPA is a progressive respiratory syndrome developing over several months to years, predominantly in patients with prior or current lung lesions-mainly cavities [15]. CPA is radiologically characterized by one or more cavities with or without a fungal ball present or nodules progressing to lung parenchymal or pleural fibrosis [15-17].

The pathogenesis of CPA is fairly well understood, especially for patients with cavitary lung diseases. Inevitable repeated exposure of persons to A. fumigatus conidia, the most frequent etiologic agent of CPA, and the small diameter $(3-5 \mu \mathrm{m})$ of these conidia facilitate their penetration into the alveoli spaces, leading to saprophytic colonization of lung cavities [18]. This may lead to local inflammation, pleural and/or parenchymal fibrosis, expansion of the colonised cavity or creation of new cavities with or without an aspergilloma (also known as a fungal ball-a complex conglomeration of fungal mycelia, fibrin, mucus, inflammatory cells and tissue debris) [5]. Fungal balls form from growth inside a pulmonary cavity that detaches from the cavity wall [19]. The role of genetic aberrations and immune dysregulation in the pathogenesis of CPA and its progression remains a subject of further investigation $[20,21]$.

\section{Epidemiology}

CPA is an emerging fungal infectious disease of public health importance [22]. Globally, it is estimated that over 3 million people suffer from CPA [12]. Of these, approximately 1.2 million cases are thought to be due to previously treated pulmonary tuberculosis (PTB) [23] and over 70,000 cases in patients with sarcoidosis [24]. Thus, PTB and emphysema are the most important risk factors for CPA, and the burden of CPA appears to be higher in areas of high burden of PTB (Table 1). Besides, CPA and PTB can co-exist, posing a challenge in distinguishing the two clinically. This group of patients is 
often misdiagnosed and managed as smear-negative PTB based on clinical symptoms and suggestive radiology but without microbiological evidence [25]. CPA is most commonly found amongst the middle-aged and elderly people, males and those with a low body mass index, implicating these characteristics as added risk factors for getting the disease [26-29].

Table 1. Findings of epidemiological studies on chronic pulmonary aspergillosis.

\begin{tabular}{|c|c|c|c|c|c|}
\hline $\begin{array}{c}\text { Author } \\
\text { (Reference) }\end{array}$ & Year & Country & Population & CPA Prevalence & Comment \\
\hline Page et al. [30] & 2019 & Uganda & $\begin{array}{l}284 \text { patients previously } \\
\text { treated for PTB }\end{array}$ & $6.3 \%$ & $\begin{array}{l}\text { CPA was significantly more } \\
\text { common in those with chest } \\
\text { radiography cavitation ( } 26 \% \text { vs. } \\
0.8 \% \text { ) and less frequent in HIV } \\
\text { co-infected patients ( } 3 \% \text { vs. } 6.7 \% \text { ) }\end{array}$ \\
\hline $\begin{array}{c}\text { Hedayati et al. } \\
\text { [31] }\end{array}$ & 2015 & Iran & $\begin{array}{c}124 \text { patients with TB } \\
\text { (94 current and } 30 \\
\text { previous } \mathrm{TB})\end{array}$ & $\begin{array}{c}13.7 \%: 2.4 \% \\
\text { aspergilloma and } \\
14 \% \text { CCPA }\end{array}$ & $38.7 \%$ had residual cavities after TB \\
\hline
\end{tabular}

COPD, chronic obstructive pulmonary diseases; CCPA, chronic cavitary pulmonary aspergillosis.

\section{Underlying Conditions in Chronic Pulmonary Aspergillosis}

The vast majority of patients with CPA have underlying structural lung diseases. In studies, it has been found that prior infection with PTB and non-tuberculous mycobacteria (NTM) are the most common major underlying conditions and risk factors for getting CPA, as well as other conditions like ABPA, COPD and/or emphysema, fibrocavity sarcoidosis, bullae or lung cysts, asthma, lung abscess, pneumothorax, Pneumocystis pneumonia, treated lung cancer, etc., all posing a risk in acquiring CPA [15,23,26-29,31-34]. These conditions create cavities or bullae that put patients at risk of developing $\mathrm{CPA}$, and unfortunately, many patients are found to have more than one of the conditions or a history of more than one [27].

In rare cases, conditions like rheumatoid arthritis, ankylosing spondylitis, silicosis, pneumoconiosis, incompletely resolved invasive pulmonary aspergillosis (IPA) and hyperimmunoglobulin E syndrome can also cause CPA [35]. Immunocompromised patients like those with diabetes mellitus, alcoholism, individuals receiving glucocorticoids like asthmatics are at risk of developing SAIA, a form of CPA that tends to occur in the immunocompromised [15].

There is evidence to show that genetic defects in innate immune functions like toll-like receptor (TLR) 4, interleukin15, TLR3, TLR10, etc., as well low numbers of CD19, CD56 and/or CD4 cells, are common in patients with CPA: they are therefore risk/predisposing factors for CPA [21,36-38]. NTM and COPD are associated with higher mortality rates in CPA [39]. Up to 10\% of CPA patients have no identifiable risk factors (Table 2). Perhaps these are the patients who may be worked up for immunological defects. 
Table 2. Underlying conditions in chronic pulmonary aspergillosis.

\begin{tabular}{cc}
\hline Underlying Condition & Frequency \\
\hline Tuberculosis & $17-80 \%$ \\
COPD \pm Emphysema & $30-50 \%$ \\
NTM infection & $<20 \%$ \\
Pneumothorax or bullous lung disease & $9-20 \%$ \\
ABPA & $12-18 \%$ \\
Pulmonary fibrocystic sarcoidosis & $9-17 \%$ \\
Lung irradiation & $\sim 5 \%$ \\
Rheumatoid arthritis & $2-4 \%$ \\
Ankylosing spondylitis & $<5 \%$ \\
None & $2-10 \%$ \\
\hline
\end{tabular}

ABPA, allergic bronchopulmonary aspergillosis; COPD, chronic obstructive pulmonary aspergillosis. Data from Denning et al. [40] and Smith et al. [27].

\section{Diagnosis: The Clinical, Radiologic, Immunologic and Microbiologic (CRIM) Approach}

$\mathrm{CPA}$ is an overlooked respiratory disease in which delay in making a correct diagnosis and commencement of an appropriate treatment is associated with increased morbidity and mortality [39]. Early identification of predisposing factors and of the patients at risk will improve treatment outcomes of CPA. Diagnosis of CPA is challenging and requires a systematic approach to assessment and interpretation of findings, both of which are necessary for correct disease classification and selection of targeted antifungal treatment and duration of said treatment [41]. Diagnosis of CPA requires a corroboration of a combination of diagnostic armamentaria i.e., Clinical, Radiological, Immunological and Mycological modalities (CRIM) (Figure 2). Current criteria for the diagnosis of CPA are summarised in Table 3 below. The Global Fungal Infection Forum (GFIF) II criteria established by the Global Action Fund for Fungal Infection (GAFFI) in collaboration with international expert panel was particularly developed for the diagnosis of CPA in resource-constrained settings [32].

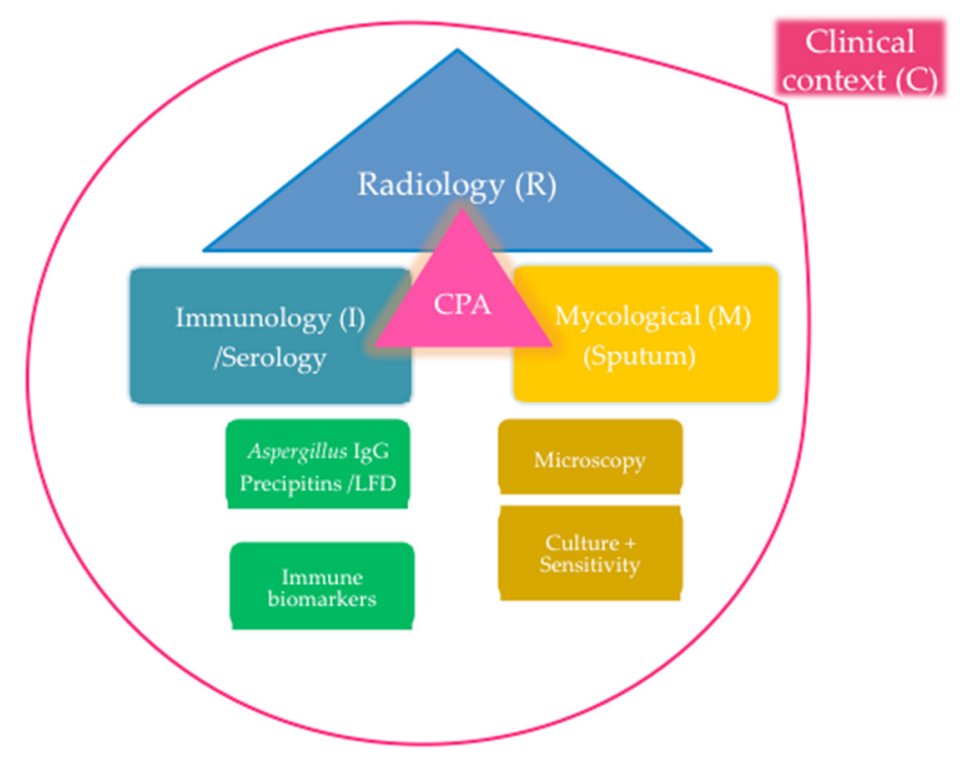

Figure 2. The Clinical, Radiological, Immunological and Mycological (CRIM) approach to the diagnosis of chronic pulmonary aspergillosis. LFD, lateral flow device; CPA, chronic pulmonary aspergillosis; PCR, polymerase chain reaction. The red circle emphasizes the fact that clinical, radiological and microbiological findings should be interpreted with respect to the patient's clinical presentation. 
Table 3. Diagnostic criteria for chronic pulmonary aspergillosis.

\begin{tabular}{|c|c|c|c|c|c|}
\hline Criteria & ESCMID/ERS/ECMM [42] & & IDSA [43] & GFIF II (GAFFI) [32] & \\
\hline 1 & $\begin{array}{l}\text { One or more cavities with or } \\
\text { without a fungal ball present or } \\
\text { nodules on thoracic imaging }\end{array}$ & All present for $\geq 3$ months & $\begin{array}{l}\text { Three months of chronic pulmonary } \\
\text { symptoms or chronic illness or progressive } \\
\text { radiographic abnormalities, with cavitation, } \\
\text { pleural thickening, pericavitary infiltrates } \\
\text { and sometimes a fungus ball }\end{array}$ & $\begin{array}{l}\text { Weight loss, persistent cough } \\
\text { and/or haemoptysis }\end{array}$ & All present for $\geq 3$ months \\
\hline 2 & $\begin{array}{l}\text { Direct evidence of Aspergillus } \\
\text { infection or an immunological } \\
\text { response to Aspergillus spp. }\end{array}$ & - & $\begin{array}{l}\text { Aspergillus IgG antibody elevated or other } \\
\text { microbiological data }\end{array}$ & $\begin{array}{l}\text { A positive Aspergillus IgG assay } \\
\text { result or other evidence of } \\
\text { Aspergillus infection. }\end{array}$ & - \\
\hline 3 & $\begin{array}{c}\text { Exclusion of alternative } \\
\text { diagnosis }\end{array}$ & - & $\begin{array}{c}\text { No or minimal immunocompromise, usually } \\
\text { with one or more underlying pulmonary } \\
\text { disorders }\end{array}$ & $\begin{array}{l}\text { Chest images showing } \\
\text { progressive cavitary infiltrates } \\
\text { and/or a fungal ball and/or } \\
\text { pericavitary fibrosis or infiltrates } \\
\text { or pleural thickening; and }\end{array}$ & - \\
\hline
\end{tabular}

Confederation of Medical Mycology; IDSA: Infectious Diseases Society of America; GFIF, Global Fungal Infection Forum; GAFFI, Global Action Fund for Fungal Infections. 
There is no single modality diagnostic for CPA. For example, a positive sputum Aspergillus culture may mean contamination, colonisation or infection; cavitary lung disease on imaging has a myriad of differential diagnoses, and many infectious and non-infectious diseases can present with constitutional symptoms, cough, sputum production and haemoptysis [44,45]. Therefore, it is important to differentiate CPA from other diseases that have a similar presentation and yet different management and prognosis.

\subsection{Clinical Diagnosis}

There is no known pathognomonic clinical feature of CPA. Individuals with CPA vary in age from young adults to those over 80 years of age, with an unclear predilection to middle-aged and elderly male persons $[15,17]$. It is noteworthy that the early stages of CPA are typically asymptomatic or clinically subtle, with symptoms appearing in a later phase of the disease [46]. Some patients present after 2-10 years of symptoms [15], typically with overt complications.

CPA characteristically presents with a history of cough (usually productive), haemoptysis and weight loss slowly developing over months ( $>3$ months) to years in an apparently immunocompetent or subtly immunocompromised patient with prior or current lung disease [46]. The haemoptysis can be minor or significant and life-threatening (i.e., greater than $150 \mathrm{~mL} /$ day) [47]. Patients may also present with non-specific symptoms such as fatigue, chest discomfort, shortness of breath and, though unusual, fever and night sweats; these systemic symptoms provide a distinction between chronic cavitary pulmonary aspergillosis (CCPA) and a simple aspergilloma in which they do not occur $[15,48,49]$.

\subsection{Radiology}

Computed tomography (CT) scans are beneficial in the characterisation of the precise disease pattern and the extent of parenchymal and pleural involvement. On the other hand, chest X-ray (CXR) is important in ruling out CPA if negative: in one study, absence of cavitation and pleural thickening on chest radiography had $100 \%$ negative predictive value for CPA [30]. Commonly observed with these modalities is the highly distinctive aspergilloma: appearing as an upper lobe lesion with an air crescent/cavity surrounded by pleural thickening $[46,50]$. This radiographic appearance of the simple aspergilloma remains stable over several months [19].

In addition to a fungal ball (aspergilloma) [Figure 3], other radiological features include a cavitary lesion with paracavitary thickening/fibrosis, and/or a new cavity or expanding cavities on serial imaging [26,42]. The most common form of CPA presents as CCPA, which when untreated may progress to chronic fibrosing pulmonary aspergillosis (CFPA). Less common is the Aspergillus nodule and single aspergilloma [42]. CCPA initially presents as poorly defined regions of consolidation that on serial radiography and can progress to form clearly defined cavities: these cavities, which may contain fungus balls, debris or fluid, are usually thin-walled with little to no associated pleural thickening, although thick-walled cavities and pleural thickening can also occur [42]. Expansion of existing cavities or formation of new ones over months is characteristic of CCPA in the absence of treatment, and left untreated, CCPA may progress to CFPA [42,46]. CFPA has similar radiographic findings as CCPA, combined with substantial fibrosis; whereas SAIA presents as cavitation and consolidation progressively worsening over weeks to a few months [42].

CPA can also present radiologically as a single or multiple nodules, which may or may not cavitate: they are typically not spiculated [46,51]. Unfortunately, because the radiological finding of nodules is often associated with negative Aspergillus-specific IgG/precipitins and an inability to attain a diagnostic biopsy, this presentation and therefore the diagnosis is often missed [16,46]. Radiological appearance of nodules may denote lung carcinoma as a possible differential diagnosis, which needs to be ruled out by histological assessment of a nodule biopsy [51].

Use of nuclear medicine modalities for the diagnosis and monitoring of CPA disease activity is not routine. 


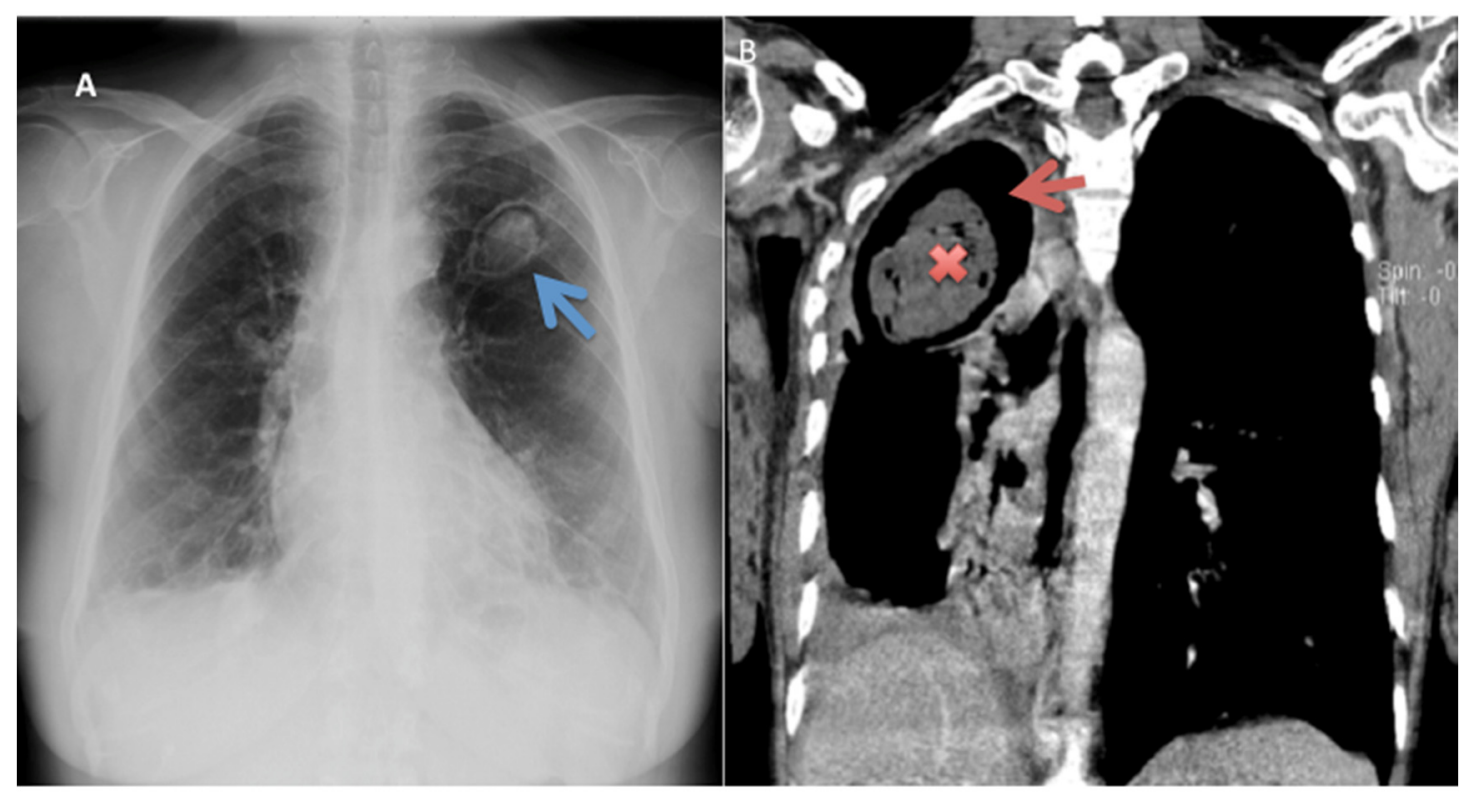

Figure 3. A chest X-ray of a 56-year-old woman with previously treated pulmonary tuberculosis (PTB) showing left apical thick-walled cavity with a well-circumscribed fungal ball (blue arrow) (A). A chest computed tomography of a 45-year old man with underlying diabetes and previously treated for PTB showing a fungal ball $(X)$ and an air-crescent sign (red arrow), typical of chronic cavitary pulmonary aspergillosis (B). Images courtesy of Dr. Felix Bongomin.

\subsection{Immunological/Serological Tests}

Serological diagnosis of CPA relies heavily on the demonstration of Aspergillus-specific immunoglobulin (Ig) G antibody or Aspergillus precipitins. Raised levels of Aspergillus-specific IgG antibodies are almost always found in CPA. Aspergillus-specific IgG is positive in over $90 \%$ of patients with CPA, while Aspergillus precipitins, though done, are less sensitive [52,53]. In this context, different methods are currently being exploited in the detection of $A$. fumigatus antibodies in blood. These tests mainly use principles of enzyme-linked immunosorbent assay (ELISA), immunodiffusion and immunoelectrophoresis.

Several tests that check for $A$. fumigatus IgG and IgM antibodies are commercially available in spite of their incomplete validation. Aspergillus-specific IgG levels have been successfully used to monitor response of CPA to medical therapy. At a cut-off value of $27 \mathrm{mgA} / \mathrm{L}$, A. fumigatus-specific IgG (Phadia) is a reliable test with high sensitivity and specificity in the diagnosis of CPA [54]. However, similar studies have shown that using the ImmunoCAP system, a cut-off of $40 \mathrm{mg} / \mathrm{L}$ appears sub-optimal for CPA diagnosis and may require revision in this context [55]. Commonly used tests are the enzyme-linked immunosorbent assay (ELISA) and a new Lateral Flow Device (LFD) (Figure 4).

ELISA has been used for detection of Aspergillus-specific IgG antibodies in patients for years, with the most common types used being the competitive and the sandwich type. For diagnosis of CPA, ELISA can be completely automated or done manually but most are done manually [52,55-57]. ELISA specificity and sensitivity in testing varies depending on the manufacturer, with the preferred recommended assay sensitivity and specificity being $90 \%$ and $85 \%$, respectively, for more accurate results [32]. LFD tests have been around for years and have been used in different medical settings, for instance, in the diagnosis of rheumatoid arthritis and as pregnancy test kits [58,59]. They are now available for Aspergillus-specific antibodies detection, with the LDBio Aspergillus immunochromatographic LFD being the only commercially available one; this specific assay possesses an $88.9-91.6 \%$ sensitivity and $96.3-98 \%$ specificity, comparable with ELISA tests presently in use [60,61]. LFD tests are advantageous in that they are inexpensive, easy to use, point-of-care diagnostic methods that have a very short turnaround time compared to other related diagnostic methods; they are therefore ideal for use in resource-limited settings and ease diagnostic testing. [46,62]. LFD tests 
therefore meet the World Health Organization ASSURED criteria for being Affordable, Sensitive, Specific, User-friendly, Rapid and robust, Equipment-free, and Deliverable to end users, even though they have not yet been used quantitatively or semi-quantitatively. [63] Aspergillus-specific IgG LFD should therefore be considered and listed on the WHO essential diagnostic list, as it has a particular unmet need in low- and middle-income countries (LMICs).

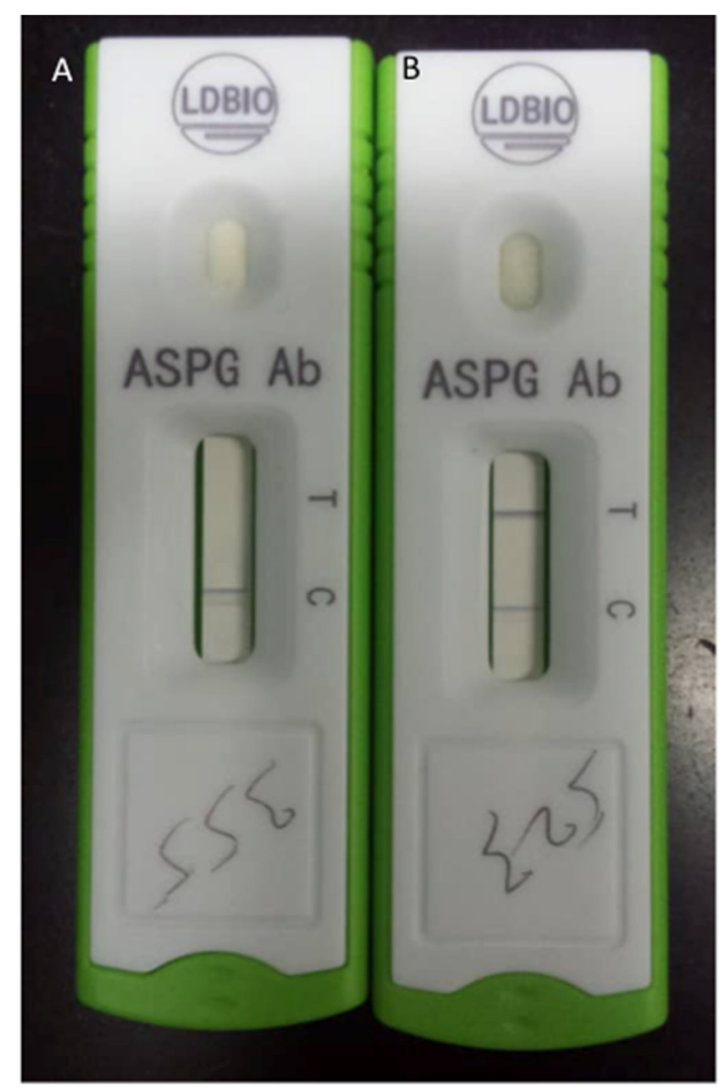

Figure 4. A negative (A, single line) and a positive (B, double line) Aspergillus-specific IgM/IgG in a patient with a suspected chronic pulmonary aspergillosis. Images courtesy of Mr. Richard Kwizera.

Notably, most Aspergillus IgG tests detect A. fumigatus IgG because A. fumigatus is the most common cause of CPA [33]. Therefore, in cases where a patient with highly suspicious findings has a negative Aspergillus IgG test, it is recommended that an alternative Aspergillus specific IgG for non-fumigatus Aspergillus species be done, as other species like A. flavus, A. terreus and A. niger can also cause CPA $[35,64]$.

\subsection{Microbiological}

Clinically or radiologically diagnosed CPA requires microbiological investigations to confirm the diagnosis. These include serology as described above, direct microscopy and fungal cultures and identification, as well as antifungal susceptibility testing [65]. Direct microscopy allows rapid presumptive identification of fungal pathogens usually to genus level, and it is from direct microscopy that the decision of particular culture media and subsequent procedures is made. Presumptive identification also guides selection of appropriate antifungal agents. However, culture of respiratory samples should be performed irrespective of the results of microscopy findings. The method involves mounting the clinical specimen on a microscopic glass slide with $10 \%$ potassium hydroxide $(\mathrm{KOH})$ [31]. Conventional culture of Aspergillus species from sputum or bronchoalveolar lavage fluid (BALF) samples has low to medium sensitivity of about $10-40 \%$, with a turnaround time of about 3-14 days. Galactomanann is a cell wall constituent of Aspergillus and other fungal pathogens and has been 
used as a biomarker for diagnosis of invasive aspergillosis. BALF galactomannan test has a sensitivity and specificity of about $38-50 \%$ and $87-100 \%$ for the diagnosis of CPA $[54,66]$. The use of BALF galactomannan tests is challenging in resource-limited settings given that bronchoscopy is not routinely performed. High-volume culture methods, however, have good sensitivity in recovering Aspergillus spp. from samples, increasing the chance of identification $[67,68]$. Multiple sputum samples probably increases culture yield.

\subsection{Other Relevant Tests}

Polymerase chain reaction (PCR) and pyrosequencing are the other methods that can detect polymorphisms of CPA-causing Aspergillus spp. and antifungal resistance. These are culture-independent molecular methods with higher sensitivity because they can detect small amounts of DNA of causative agents in the patient samples; regarding detection of CPA-causing Aspergillus spp., PCR has an average sensitivity and specificity of approximately $80 \%$ [69-71].

\section{Management Approach}

Considering CPA represents a spectrum of diseases, its optimal management will vary depending on the clinical presentation of the patient and the radiological phenotype of the disease, i.e., Aspergillus nodule, simple aspergilloma, CCPA and CFPA (see below). A multidisciplinary approach is key in the management of patients with CPA. A comprehensive management approach requires a combination of close monitoring, and medical (antifungal therapy, usually oral), surgical and radiological interventions.

The overall management goals in CPA are as follows:

1. To improve symptoms and patients' 'functional status'—quality of life

2. To prevent the progressive destruction of lung tissue and the development of pulmonary fibrosis

3. To arrest or prevent haemoptysis

4. To prevent the emergence of antifungal resistance

5. To avoid antifungal toxicity

6. To reduce death rates and morbidity

\subsection{Simple Aspergilloma}

In patients with simple aspergilloma, those that are asymptomatic and clinically stable for a period of 6 months to 2 years are continually closely monitored and do not need antifungal treatment; for those that are symptomatic, especially presenting with potentially life-threatening haemoptysis, surgical resection is recommended as a definitive cure, as long as the patients have adequate pulmonary function [42,72]. Aspergillomas can spontaneously resolve, but that has been noted in less than $10 \%$ of cases [73]. In patients with poor pulmonary function, surgery on the aspergilloma is mostly contraindicated because of post-operative pulmonary deterioration or broncho-pleural fistulae, which can be fatal [74]. Bronchial artery embolisation (BAE) is therefore employed in these cases as it is a less invasive technique than surgery that can be used as a short-term control against haemoptysis until the patients are fit to undergo surgery, or are started on antifungal therapy $[75,76]$.

Antifungal therapy has limited benefit in the treatment of a simple aspergilloma: it is reserved for symptomatic patients who are unable to undergo surgery, as well as those who are immunocompromised or have radiologic progression [77-80]. The antifungal regimen used is the same as that of CCPA and CFPA (see below). Antifungal therapy, such as voriconazole, can be given at pre- and post-operative periods to reduce the likelihood of post-operative pleural aspergillosis in case of spillage from the cavity being accidentally opened during surgery [77], and relapse.

Radiological monitoring of patients with aspergilloma is best done with low-dose CT scanning at an estimated interval of every 6-12 months in the immunocompromised and less often in the immunocompetent: this is done to assess disease progression and treatment effectiveness. However, if new symptoms emerge, especially haemoptysis, it is also an indicator for additional imaging and 
investigation for other infectious agents [77]. A noted persistent elevation of Aspergillus IgG titres may suggest treatment failure.

\subsection{CCPA and CFPA}

Patients with CCPA and CFPA that are asymptomatic with stable disease do not require antifungal therapy, but should be carefully monitored with objective parameters (imaging, lung function and Aspergillus IgG titers. However, for those who are symptomatic with radiographically and serologically progressive disease, antifungal therapy is indicated [77]. Oral triazoles are the mainstay or therapy, as they are known to be active against Aspergillus spp. and are relatively well tolerated; the one exception being fluconazole, which has no effect on Aspergillus spp. These drugs act by interfering with cell membrane synthesis in susceptible Aspergillus spp. by inhibiting the enzyme lanosterol 14 alpha-demethylase, hence preventing ergosterol conversion from lanosterol [81].

For CCPA therapy, the first-line is oral itraconazole ( $200 \mathrm{mg}$ twice daily) or voriconazole ( $150 \mathrm{mg}$ to $200 \mathrm{mg}$ twice daily), both with therapeutic drug level monitoring, which is impractical in most centres in sub-Saharan Africa. The aim of the therapy is to improve or prevent symptoms as well as reduce progression of fibrosis $[43,82,83]$. At present, the choice between the two is based on cost, availability, toxicity and tolerability; they are therefore used interchangeably as first-line agents $[81,82]$. Treatment for at least 6 months is sufficient for patients with limited disease; for those with bilateral or extensive disease, 24 months or life-long treatment may be required to avoid relapse following discontinuation of therapy [84]. However, voriconazole is preferred for large aspergillomas and patients with more severe disease (bilateral disease) [85]. Itraconazole has been found to show a mean overall 6-month response rate in CPA cases of 63-76.5\%; regrettably, it has been associated with adverse effects in about $40-50 \%$ cases: some of these adverse effects include gastrointestinal upset, ankle edema, hypertension, peripheral neuropathy, hair loss, etc. [77,81,86,87]. However, these side effects may be lower in LMICs since the patients are much younger and are more likely to tolerate these drugs [25,87]. Voriconazole has been reported to have a response rate of $64 \%$ at 3 months and $32 \%$ at 6 months, but has also been noted to have more common occurrences of adverse reactions that include transient and reversible visual disturbance, papilledema, optic neuritis, hepatotoxicity, fluorosis, QTc prolongation and photosensitivity with an associated risk of developing skin malignancies in pale skinned, immunosuppressed people [68,88-90].

All triazoles inhibit CYP3A4, and voriconazole also CYP2C9 and CYPC19 and thus have great potential for drug-drug interactions with several over-the-counter drugs that can lead to medical complications in patients [91-93].

Intravenous drug therapy singly or in combination with azoles is a last resort following clinical failure, pan-azole resistance or drug toxicity, but can also be used in some situations of severe illness presentation. The intravenous drugs used include amphotericin B or an echinocandin, usually micafungin or caspofungin $[43,81]$. However, due to the significance of the nephrotoxicity associated with the intermittent or long-term use of amphotericin $B$, some practitioners prefer to use echinocandins [94,95]. One of the authors (DWD) noted that a week course of intravenous amphotericin $B$ does last some patients months and can be followed by itraconazole maintenance therapy, with good disease control. This may be due to the immunological stimulus that amphotericin gives. Micafungin is the echinocandin of choice for CPA therapy because it is the only one that has been extensively studied: its efficacy over 4 weeks is similar to that of voriconazole, reaching up to $68 \%$ with reduced side effects and drug interactions; it is therefore safer in the treatment of CCPA and SAIA [94,96-98]. Courses given are usually 150-300 mg/day for a duration of 3-12 weeks [94,97,98]. Caspofungin has similar efficacy to micafungin [98].

Surgery, commonly a lobectomy, can be considered in CCPA with severe haemoptysis or failed therapy, but it is associated with a high rate of post-operative complications and the possibility of recurrence [99-101]. Patients need to be given antifungals before and peri-operatively, if possible, to avoid post-operative complications. 
CFPA requires antifungal therapy, as mentioned for CCPA, and additional supportive treatment of antibiotics for concurrent bacterial infections, oxygen support, physiotherapy, adjunctive interferon-gamma injections, etc. [102,103]. Weekly interferon-gamma injections have been shown to reduce acute exacerbations and hospitalizations for CPA [104].

\subsection{Aspergillus Nodule}

Surgery is the first-line therapy, especially if lung cancer cannot be ruled out, and these patients should not receive antifungal therapy unless symptomatic, but ought to be followed up with serial imaging and Aspergillus antibody titres to detect infection relapse [77,101]. For symptomatic patients without access to surgical interventions, treatment is the same as for CCPA/CFPA above.

\section{Prognosis of Treated CPA}

There is no clear consensus on what constitutes treatment success or cure of CPA, yet this would be a fundamental point for estimating survival. Studies have used composite outcomes that include improvement in signs and symptoms, resolution of radiological findings and mycological evaluation $[26,87,105]$. Chest CT imaging seems to be the only objective measure of treatment response that correlates with clinical response [106]. However, weight gain, improvement of respiratory symptoms and a reduction in the IgG have also been used as treatment endpoints [85].

\section{CPA Recurrence}

After discontinuation of antifungal therapy, relapse occurs in up to $36 \%$ of CPA patients with a median duration of 120-160 days and is predicted by bilateral pulmonary disease and involvement of more than one lobe $[84,107]$.

Relapse/recurrence of CPA has been associated with younger age, multi-lobar disease, slow radiological resolution, and prolonged therapy with antifungal drugs [87]. In a study done by Koyama and colleagues, recurrence of CPA was found in about a third of cases post azole treatment discontinuation: the study looked at patients who achieved resolution of clinical, serological and radiographic manifestations of CPA and stopped taking antifungal triazoles [107]. In other studies, it was noted that relapse of CCPA is common after discontinuation of therapy, as is the case with CFPA $[87,108]$. Aspergillomas have a low recurrence rate. [109].

In studies where patients underwent surgical management of CPA, with or without accompanying anti-fungal therapy and other procedures, recurrence of CPA was found to still be an issue, noted especially with CCPA. [101]. There is indeed need for more large-scale detailed research into recurrence of CPA to get a clearer picture of it.

\section{CPA Mortality and Predictors}

There are limited data on studies from resource-limited settings that have reported survival data among patients with CPA. In the UK, the 1-, 5- and 10-year survival in intensively treated patients has been reported to be $86 \%, 62 \%$ and $47 \%$, respectively [39]. In Japan, a similar estimate of $83 \%$ after 1 year and $61 \%$ after 5 years is reported among patients who had a history of pulmonary NTM disease [110]. However, Ohba et al. reported a 50\% mortality among patients with CPA in a small study in Japan [33]. CPA survival is affected by the clinical and radiological phenotypes of the patients. Patients with SAIA are reported to have a poor prognosis, with $51 \%$ of patients dying within 18 months [111]. Conversely, the 2-year survival among patients with CCPA was $72.4 \%$ and was comparable to survival among patients with simple aspergilloma [112]. However, following surgical intervention, the 10-year survival of simple pulmonary nodule is $69-90 \%$ while that of CCPA is approximately $63-80 \%$ [101]

Studies reporting predictors of mortality among patients with CPA are limited by small sample sizes. In Iran, predictors of mortality were diabetes, hypoxic respiratory failure and length of hospital stay [113]. Lowes et al. reported mortality to be associated with NTM, COPD, low albumin, higher age, a low activity score on the St. George Respiratory Questionnaire (SGRQ) and imaging findings 
consistent with bilateral aspergillomas, cavitary disease and pleural involvement in a large study in the UK [39]. Among patients with NTM-related CPA, an elevated C-reactive protein and the use of corticosteroids seem to predict mortality [110]. Other predictors of mortality reported, albeit in small studies, are low body mass index, a higher total leucocyte count, a lower platelet count and elevated liver enzymes [114].

\section{Conclusions}

In conclusion, CPA occurs in patients with underlying lung diseases such as previous TB, atypical mycobacteria, COPD, sarcoidosis or lung cancer. Its clinical presentation and radiological features overlap substantially with the underlying diseases themselves. Long-term oral triazole therapy is the mainstay for the management of CPA, with itraconazole and voriconazole both being effective. Key challenges with long-term triazole therapy include, antifungal resistance, adverse events, intolerance and drug-drug interactions. Intravenous amphotericin B or echinocandins are useful after failure of oral azole therapy. Relapse of CPA symptoms are common following discontinuation of long-term maintenance therapy.

Author Contributions: F.B. conceived the manuscript. F.B., L.G.A., J.B.B. and R.K. participated in initial manuscript drafting. F.B., L.G.A., J.B.B., R.K. and D.W.D. participated in critical revisions for intellectual content and material support. All authors have read and agreed to the published version of the manuscript.

Funding: This research received no specific grant from any funding agency in the public, commercial, or not-for-profit sectors.

Conflicts of Interest: The authors declare no conflict of interest.

\section{References}

1. Bennett, J. On the parasitic vegetable structures found in living animals. Trans. R. Soc. Edinb. 1842, 15, 277-279. [CrossRef]

2. Samson, R.A.; Visagie, C.M.; Houbraken, J.; Hong, S.-B.; Hubka, V.; Klaassen, C.H.W.; Perrones, G.; Seifert, K.A.; Susca, A.; Tanney, J.B.; et al. Phylogeny, identification and nomenclature of the genus Aspergillus. Stud. Mycol. 2014, 78, 343-371. [CrossRef]

3. Sugui, J.A.; Kwon-Chung, K.J.; Juvvadi, P.R.; Latge, J.-P.; Steinbach, W.J. Aspergillus fumigatus and Related Species. Cold Spring Harb. Perspect. Med. 2015, 5, a019786. [CrossRef]

4. Ullmann, A.J.; Aguado, J.M.; Arikan-Akdagli, S.; Denning, D.W.; Groll, A.H.; Lagrou, K.; Lass-Flörl, C.; Lewis, R.E.; Munoz, P.; Verweij, P.E.; et al. Diagnosis and management of Aspergillus diseases: Executive summary of the 2017 ESCMID-ECMM-ERS guideline. Clin. Microbiol. Infect. 2018, 24 (Suppl. 1), e1-e38. [CrossRef] [PubMed]

5. Denning, D.W. Introduction. In Aspergillosis: From Diagnosis to Prevention; Comarú Pasqualotto, A., Ed.; Springer: Dordrecht, The Netherlands, 2010; pp. 3-5. [CrossRef]

6. Smith, J.A.; Kauffman, C.A. Pulmonary fungal infections. Respirology 2012, 913-926. [CrossRef] [PubMed]

7. Takazono, T.; Sheppard, D.C. Aspergillus in chronic lung disease: Modeling what goes on in the airways. Med. Mycol. 2016, 55, 39-47. [CrossRef] [PubMed]

8. Bongomin, F.; Batac, C.R.; Richardson, M.D.; Denning, D.W. A Review of Onychomycosis Due to Aspergillus Species. Mycopathologia 2018, 183, 485-493. [CrossRef]

9. Queiroz-Telles, F.; Fahal, A.H.; Falci, D.R.; Caceres, D.H.; Chiller, T.; Pasqualotto, A.C. Neglected endemic mycoses. Lancet Infect. Dis. 2017, 17, e367-e377. [CrossRef]

10. Muldoon, E.G.; Strek, M.E.; Patterson, K.C. Allergic and Noninvasive Infectious Pulmonary Aspergillosis Syndromes. Clin. Chest Med. 2017, 38, 521-534. [CrossRef]

11. Sherif, R.; Segal, B.H. Pulmonary Aspergillosis: Clinical presentation, diagnostic tests, management and complications. Curr. Opin. Pulm. Med. 2010, 16, 242-250. [CrossRef]

12. Bongomin, F.; Gago, S.; Oladele, R.; Denning, D. Global and Multi-National Prevalence of Fungal Diseases-Estimate Precision. J. Fungi 2017, 3, 57. [CrossRef] [PubMed]

13. Brown, G.D. Hidden killers: Human fungal infections. Sci. Transl. Med. 2012, 4, 165rv13. [CrossRef] [PubMed] 
14. Mortezaee, V.; Mahdaviani, S.A.; Mirenayat, M.S.; Pourabdollah, M.; Hassanzad, M.; Mehrian, P.; Maleki, M.; Heshmatnia, J.; Fakharian, A.; Bongomin, F.; et al. The Complications of Aspergillus fumigatus Sensitization in Patients with Asthma. Jundishapur J. Microbiol. Kowsar 2020, 13, e99833. [CrossRef]

15. Denning, D.W.; Riniotis, K.; Dobrashian, R.; Sambatakou, H. Chronic Cavitary and Fibrosing Pulmonary and Pleural Aspergillosis: Case Series, Proposed Nomenclature Change, and Review. Clin. Infect. Dis. 2003, 37, S265-S280. [CrossRef]

16. Muldoon, E.G.; Sharman, A.; Page, I.; Bishop, P.; Denning, D.W. Aspergillus nodules; another presentation of Chronic Pulmonary Aspergillosis. BMC Pulm. Med. 2016, 16, 123. [CrossRef]

17. Kosmidis, C.; Denning, D.W. The clinical spectrum of pulmonary aspergillosis. Postgr. Med. J. 2015, 91, 270-277. [CrossRef]

18. Kwon-Chung, K.J.; Sugui, J.A. Aspergillus fumigatus-What Makes the Species a Ubiquitous Human Fungal Pathogen? PLoS Pathog. 2013, 9, e1003743. [CrossRef]

19. Roberts, C.M.; Citron, K.M.; Strickland, B. Intrathoracic aspergilloma: Role of CT in diagnosis and treatment. Radiology 1987, 165, 123-128. [CrossRef]

20. Harrison, E.; Singh, A.; Morris, J.; Smith, N.L.; Fraczek, M.G.; Moore, C.B.; Denning, D.W. Mannose-binding lectin genotype and serum levels in patients with chronic and allergic pulmonary aspergillosis. Int. J. Immunogenet. 2012, 39, 224-232. [CrossRef]

21. Bongomin, F.; Harris, C.; Foden, P.; Kosmidis, C.; Denning, D.W. Innate and Adaptive Immune Defects in Chronic Pulmonary Aspergillosis. J. Fungi 2017, 3, 26. [CrossRef]

22. Denning, D.W. Minimizing fungal disease deaths will allow the UNAIDS target of reducing annual AIDS deaths below 500000 by 2020 to be realized. Philos. Trans. R. Soc. B 2016, 371, 20150468. [CrossRef] [PubMed]

23. Denning, D.W.; Pleuvry, A.; Cole, D.C. Global burden of chronic pulmonary aspergillosis as a sequel to pulmonary tuberculosis. Bull. World Health Organ. 2011, 89, 864-872. [CrossRef] [PubMed]

24. Denning, D.W.; Pleuvry, A.; Cole, D.C. Global burden of chronic pulmonary aspergillosis complicating sarcoidosis. Eur. Respir. J. 2013, 41, 621-626. [CrossRef] [PubMed]

25. Oladele, R.O.; Irurhe, N.K.; Foden, P.; Akanmu, A.S.; Gbaja-Biamila, T.; Nwosu, A.; Ekundayo, H.A.; Ogunsola, F.T.; Richardson, M.D.; Denning, D.W. Chronic pulmonary aspergillosis as a cause of smear-negative TB and/or TB treatment failure in Nigerians. Int. J. Tuberc. Lung Dis. 2017, 21, 1056-1061. [CrossRef] [PubMed]

26. Jhun, B.W.; Jeon, K.; Eom, J.S.; Lee, J.H.; Suh, G.Y.; Kwon, O.J.; Koh, W.J. Clinical characteristics and treatment outcomes of chronic pulmonary aspergillosis. Med. Mycol. 2013, 51, 811-817. [CrossRef] [PubMed]

27. Smith, N.L.; Denning, D.W. Underlying conditions in chronic pulmonary aspergillosis including simple aspergilloma. Eur. Respir. J. 2011, 37, 865-872. [CrossRef]

28. Camara, B.; Reymond, E.; Saint-Raymond, C.; Roth, H.; Brenier-Pinchart, M.-P.; Pinel, C.; Cadranel, J.; Ferretti, G.; Pelloux, H.; Pison, C. Characteristics and outcomes of chronic pulmonary aspergillosis: A retrospective analysis of a tertiary hospital registry. Clin. Respir. J. Engl. 2015, 9, 65-73. [CrossRef]

29. Benjelloun, H.; Zaghba, N.; Yassine, N.; Bakhatar, A.; Karkouri, M.; Ridai, M.; Bahlaoui, A. Chronic pulmonary aspergillosis: A frequent and potentially severe disease. Méd. Mal. Infect. 2015, 45, 128-132. [CrossRef]

30. Page, I.D.; Byanyima, R.; Hosmane, S.; Onyachi, N.; Opira, C.; Richardson, M.; Sawyer, R.; Sharman, A.; Denning, D.W. Chronic pulmonary aspergillosis commonly complicates treated pulmonary tuberculosis with residual cavitation. Eur. Respir. J. 2019, 53, 1801184. [CrossRef]

31. Hedayati, M.T.; Azimi, Y.; Droudinia, A.; Mousavi, B.; Khalilian, A.; Hedayati, N.; Denning, D.W. Prevalence of chronic pulmonary aspergillosis in patients with tuberculosis from Iran. Eur. J. Clin. Microbiol. Infect. Dis. 2015, 34, 1759-1765. [CrossRef]

32. Denning, D.W.; Page, I.D.; Chakaya, J.; Jabeen, K.; Jude, C.M.; Cornet, M.; Alastruey-Izquierdo, A.; Bongomin, F.; Bowyer, P.; Chakrabarti, A.; et al. Case Definition of Chronic Pulmonary Aspergillosis in Resource-Constrained Settings. Emerg. Infect. Dis. 2018, 24, e1-e13. [CrossRef] [PubMed]

33. Ohba, H.; Miwa, S.; Shirai, M.; Kanai, M.; Eifuku, T.; Suda, T.; Hayakawa, H.; Chida, K. Clinical characteristics and prognosis of chronic pulmonary aspergillosis. Respir. Med. 2012, 106, 724-729. [CrossRef]

34. Jhun, B.W.; Jung, W.J.; Hwang, N.Y.; Park, H.Y.; Jeon, K.; Kang, E.S.; Koh, W.J. Risk factors for the development of chronic pulmonary aspergillosis in patients with nontuberculous mycobacterial lung disease. PLoS ONE 2017, 12, e0188716. [CrossRef] 
35. Denning, A.D.W. Clinical manifestations and diagnosis of chronic pulmonary aspergillosis. Eur. Respir. J. 2020, 8, 1-24.

36. Carvalho, A.; Pasqualotto, A.C.; Pitzurra, L.; Romani, L.; Denning, D.W.; Rodrigues, F. Polymorphisms in toll-like receptor genes and susceptibility to pulmonary aspergillosis. J. Infect. Dis. 2008, 197, 618-621. [CrossRef]

37. Smith, N.L.D.; Hankinson, J.; Simpson, A.; Bowyer, P.; Denning, D.W. A prominent role for the IL1 pathway and IL15 in susceptibility to chronic cavitary pulmonary aspergillosis. Clin. Microbiol. Infect. Eur. Soc. Clin. Infect. Dis. 2014, 20, O480-O488. [CrossRef] [PubMed]

38. Smith, N.L.D.; Hankinson, J.; Simpson, A.; Denning, D.W.; Bowyer, P. Reduced expression of TLR3, TLR10 and TREM1 by human macrophages in Chronic cavitary pulmonary aspergillosis, and novel associations of VEGFA, DENND1B and PLAT. Clin. Microbiol. Infect. Eur. Soc. Clin. Infect. Dis. 2014, 20, O960-O968. [CrossRef] [PubMed]

39. Lowes, D.; Al-Shair, K.; Newton, P.J.; Morris, J.; Harris, C.; Rautemaa-Richardson, R.; Denning, D.W. Predictors of mortality in chronic pulmonary aspergillosis. Eur. Respir. J. 2017, 49, 1601062. [CrossRef]

40. Denning, D.W.; Chakrabarti, A. Pulmonary and sinus fungal diseases in non-immunocompromised patients. Lancet Infect. Dis. 2017, 17, e357-e366. [CrossRef]

41. Davidsen, J.R.; Rosenvinge, F.S.; Assing, K.; Laursen, C.B. Chronic Pulmonary Aspergillosis. 2018. Available online: http://www.ncbi.nlm.nih.gov/pubmed/29393028 (accessed on 25 May 2020).

42. Denning, D.W.; Cadranel, J.; Beigelman-Aubry, C.; Ader, F.; Chakrabarti, A.; Blot, S.; Ullmann, A.J.; Dimopoulos, G.; Lange, C. Chronic pulmonary aspergillosis: Rationale and clinical guidelines for diagnosis and management. Eur. Respir. J. 2016, 47, 45-68. [CrossRef]

43. Patterson, T.F.; Thompson, G.R.; Denning, D.W.; Fishman, J.A.; Hadley, S.; Herbrecht, R.; Kontoyiannis, D.P.; Marr, K.A.; Morrison, V.A.; Nguyen, M.H.; et al. Practice Guidelines for the Diagnosis and Management of Aspergillosis: 2016 Update by the Infectious Diseases Society of America. Clin. Infect. Dis. 2016, 63, e1-e60. [CrossRef] [PubMed]

44. Hayes, G.; Novak-Frazer, L. Chronic Pulmonary Aspergillosis-Where Are We? and Where Are We Going? J. Fungi 2016, 2, 18. [CrossRef] [PubMed]

45. Bodey, G.P.; Vartivarian, S. Aspergillosis. Eur. J. Clin. Microbiol. Infect. Dis. 1989, 8, 413-437. [CrossRef]

46. Wilopo, B.A.P.; Richardson, M.D.; Denning, D.W. Diagnostic Aspects of Chronic Pulmonary Aspergillosis: Present and New Directions. Curr. Fungal. Infect. Rep. 2019, 13, 292-300. [CrossRef]

47. Betancourt, B.Y.; Garofoli, A.C.; Sandhu, J.S.; Boma, N.; Sy, A.M. Pulmonary aspergillosis presenting with recurrent haemoptysis. Case Rep. 2015, 2-4. [CrossRef] [PubMed]

48. Hou, X.; Zhang, H.; Kou, L.; Lv, W.; Lu, J.; Li, J. Clinical features and diagnosis of chronic pulmonary aspergillosis in Chinese patients. Medicine 2017, 96, e8315. [CrossRef]

49. Schweer, K.E.; Bangard, C.; Hekmat, K.; Cornely, O.A. Chronic pulmonary aspergillosis. Mycoses 2014, 57, 257-270. [CrossRef]

50. Desai, S.R.; Hedayati, V.; Patel, K.; Hansell, D.M. Chronic Aspergillosis of the Lungs: Unravelling the Terminology and Radiology. Eur. Radiol. 2015, 25, 3100-3107. [CrossRef]

51. Baxter, C.G.; Bishop, P.; Low, S.E.; Baiden-Amissah, K.; Denning, D.W. Pulmonary aspergillosis: An alternative diagnosis to lung cancer after positive [18F] FDG positron emission tomography. Thorax 2011, 66, 638-640. [CrossRef]

52. Dumollard, C.; Bailly, S.; Perriot, S.; Brenier-Pinchart, M.P.; Saint-Raymond, C.; Camara, B.; Gangneux, J.P.; Persat, F.; Valot, S.; Grenouillet, F.; et al. Prospective Evaluation of a New Aspergillus IgG Enzyme Immunoassay Kit for Diagnosis of Chronic and Allergic Pulmonary Aspergillosis. J. Clin. Microbiol. Am. Soc. Microbiol. 2016, 54, 1236-1242. [CrossRef]

53. Fujiuchi, S.; Fujita, Y.; Suzuki, H.; Doushita, K.; Kuroda, H.; Takahashi, M.; Yamazaki, Y.; Tsuji, T.; Fujikane, T.; Osanai, S.; et al. Evaluation of a Quantitative Serological Assay for Diagnosing Chronic pulmonary aspergillosis. J. Clin. Microbiol. 2016, 54, 1496-1499. [CrossRef] [PubMed]

54. Sehgal, I.S.; Choudhary, H.; Dhooria, S.; Aggarwal, A.N.; Garg, M.; Chakrabarti, A.; Agarwal, R. Diagnostic cut-off of Aspergillus fumigatus -specific IgG in the diagnosis of chronic pulmonary aspergillosis. Mycoses 2018, 61, 770-776. [CrossRef] [PubMed]

55. Page, I.D.; Richardson, M.D.; Denning, D.W. Comparison of six Aspergillus-specific IgG assays for the diagnosis of chronic pulmonary aspergillosis (CPA). J. Infect. 2016, 72, 240-249. [CrossRef] [PubMed] 
56. Baxter, C.G.; Denning, D.W.; Jones, A.M.; Todd, A.; Moore, C.B.; Richardson, M.D. Performance of two Aspergillus IgG EIA assays compared with the precipitin test in chronic and allergic aspergillosis. Eur. Soc. Clin. Infect. Dis. 2012, 19, E197-E204. [CrossRef] [PubMed]

57. Stubbins, J.M.; Warnock, D.W. Rapid enzyme-linked immunosorbent assay (ELISA) for Aspergillus fumigatus antibodies. J. Clin. Pathol. 1982, 35, 1134-1137.

58. Hawkes, R.; Niday, E.; Gordon, J. A dot-immunobinding assay for monoclonal and other antibodies. Anal. Biochem. 1982, 119, 142-147. [CrossRef]

59. Plotz, C.M.; Singer, J.M. The latex fixation test. I. Application to the serologic diagnosis of rheumatoid arthritis. Am. J. Med. 1956, 21, 888-892.

60. Stucky Hunter, E.; Richardson, M.D.; Denning, D.W. Evaluation of LDBio Aspergillus ICT Lateral Flow Assay for IgG and IgM Antibody Detection in Chronic Pulmonary Aspergillosis. J. Clin. Microbiol. 2019, 57, e00538-19. [CrossRef]

61. Piarroux, R.P.; Romain, T.; Martin, A.; Vainqueur, D.; Vitte, J.; Lachaud, L.; Gangneux, J.P.; Gabriel, F.; Fillaux, J.; Ranque, S. Multicenter evaluation of a novel immunochromatographic test for anti-aspergillus IgG detection. Front. Cell. Infect. Microbiol. 2019, 9, 1-7. [CrossRef]

62. Takazono, T.; Ito, Y.; Tashiro, M.; Nishimura, K.; Saijo, T.; Yamamoto, K. Evaluation of Aspergillus-Specific Lateral-Flow Device Test Using Serum and Bronchoalveolar Lavage Fluid for Diagnosis of Chronic Pulmonary Aspergillosis. J. Clin. Microbiol. 2019, 57, e00095-19. [CrossRef]

63. Klausner, J.D.; Vijayan, T.; Chiller, T. Sensitivity and specificity of a new cryptococcal antigen lateral flow assay in serum and cerebrospinal fluid. MLO Med. Lab. Obs. 2013, 45, 16.

64. Severo, L.C.; Geyer, G.R.; Porto, S.; Wagner, B.; Londero, A.T. Pulmonary Aspergillus niger intraca- vitary colonization. Report of 23 cases and a review of the literature. Rev. Iberoam. De Micol. 1997, 14, 104-110.

65. Schelenz, S.; Barnes, R.A.; Barton, R.C.; Cleverley, J.R.; Lucas, S.B.; Kibbler, C.C.; Denning, D.W. British Society for Medical Mycology best practice recommendations for the diagnosis of serious fungal diseases. Lancet Infect. Dis. 2015, 15, 461-474. [CrossRef]

66. Sehgal, I.S.; Dhooria, S.; Choudhary, H.; Aggarwal, A.N.; Garg, M.; Chakrabarti, A.; Agarwal, R. Utility of Serum and Bronchoalveolar Lavage Fluid Galactomannan in Diagnosis of Chronic Pulmonary Aspergillosis. J. Clin. Microbiol. 2019, 57, e01821-18. [CrossRef] [PubMed]

67. Vergidis, P.; Moore, C.B.; Novak-Frazer, L.; Rautemaa-Richardson, R.; Walker, A.; Denning, D.W.; Richardson, M.D. High-Volume Culture and Quantitative Real-Time PCR for the Detection of Aspergillus in Sputum. Clin. Microbiol. Infect. 2019. [CrossRef]

68. Camuset, J.; Nunes, H.; Dombret, M.C.; Bergeron, A.; Henno, P.; Philippe, B.; Dauriat, G.; Mangiapan, G.; Rabbat, A.; Cadranel, J. Treatment of chronic pulmonary aspergillosis by voriconazole in nonimmunocompromised patients. Chest 2007, 131, 1435-1441. [CrossRef]

69. Aspergillosis, P.; Urabe, N.; Sakamoto, S.; Sano, G.; Suzuki, J.; Hebisawa, A. Usefulness of Two Aspergillus PCR Assays and Aspergillus Galactomannan and Lavage Fluid for Diagnosis of Chronic. J. Clin. Microbiol. 2017, 55, 1738-1746.

70. Imbert, S.; Meyer, I.; Palous, M.; Brossas, J.; Uzunov, M.; Touafek, F.; Gay, F.; Trosini-desert, V. Aspergillus PCR in Bronchoalveolar Lavage Fluid for the Diagnosis and Prognosis of Aspergillosis in Patients With Hematological and Non-hematological Conditions. Front. Microbiol. 2018, 9, 1877. [CrossRef]

71. Fayemiwo, S.; Moore, C.B.; Foden, P.; Denning, D.W.; Richardson, M.D. Comparative performance of Aspergillus galactomannan ELISA and PCR in sputum from patients with ABPA and CPA. J. Microbiol. Methods 2017, 140, 32-39. [CrossRef]

72. Moodley, L.; Pillay, J.; Dheda, K. Aspergilloma and the surgeon. J. Thorac. Dis. 2014, 6, 202-209. [CrossRef]

73. Passera, E.; Rizzi, A.; Robustellini, M.; Rossi, G.; Della Pona, C.; Massera, F.; Rocco, G. Pulmonary aspergilloma. Clinical aspects and surgical treatment outcome. Thoracic. Surg. Clin. 2012, 345-361. [CrossRef] [PubMed]

74. He, B.; Wan, C.; Zhou, W.; Rui, Y.; Shi, Y.; Su, X. Clinical profile and surgical outcome for different types of chronic pulmonary aspergillosis. Am. J. Transl. Res. 2019, 11, 3671-3679. [PubMed]

75. Shin, B.; Koh, W.-J.; Shin, S.W.; Jeong, B.-H.; Park, H.Y.; Suh, G.Y.; Jeon, K. Outcomes of Bronchial Artery Embolization for Life-Threatening Hemoptysis in Patients with Chronic Pulmonary Aspergillosis. PLoS ONE 2016, 11, e0168373. [CrossRef] [PubMed]

76. Panda, A.; Bhalla, A.S.; Goyal, A. Bronchial artery embolization in hemoptysis: A systematic review. Diagn. Interv. Radiol. 2017, 23, 307-317. [CrossRef] 
77. El-Baba, F.; Gao, Y.; Soubani, A.O. Pulmonary Aspergillosis: What the Generalist Needs to Know. Am. J. Med. 2020. [CrossRef]

78. Campbell, J.H.; Winter, J.H.; Richardson, M.D.; Shankland, G.S.; Banham, S.W. Treatment of pulmonary aspergilloma with itraconazole. Thorax 1991, 46, 839-841. [CrossRef]

79. Lebeau, B.; Pelloux, H.; Pinel, C.; Michallet, M.; Gout, J.P.; Pison, C.; Delormas, P.; Bru, J.P.; Brion, J.P.; Ambroise-Thomas, P. Itraconazole in the treatment of aspergillosis: A study of 16 cases. Mycoses 1994, 37, 171-179. [CrossRef]

80. Dupont, B. Itraconazole therapy in aspergillosis: Study in 49 patients. J. Am. Acad. Dermatol. 1990, 23, 607-614. [CrossRef]

81. Maghrabi, F.; Denning, D.W. The Management of Chronic Pulmonary Aspergillosis: The UK National Aspergillosis Centre Approach. Curr. Fungal. Infect. Rep. 2017. [CrossRef]

82. Tashiro, M.; Takazono, T.; Saijo, T.; Yamamoto, K.; Imamura, Y.; Miyazaki, T.; Kakeya, H.; Ando, T.; Ogawa, K.; Kishi, K.; et al. Selection of Oral Antifungals for Initial Maintenance Therapy in Chronic Pulmonary Aspergillosis: A Longitudinal Analysis. Clin. Infect. Dis. 2019, 70, 835-842. [CrossRef]

83. Barac, A.; Kosmidis, C.; Alastruey-Izquierdo, A.; Salzer, H.J.; CPAnet. Chronic pulmonary aspergillosis update: A year in review. Med. Mycol. 2019, 57, S104-S109. [CrossRef] [PubMed]

84. Bongomin, F.; Otu, A.; Harris, C.; Foden, P.; Kosmidis, C.; Denning, D.W. Risk factors for relapse of chronic pulmonary aspergillosis after discontinuation of antifungal therapy. Clin. Infect. Pract. 2020, 5, 100015. [CrossRef]

85. Bongomin, F.; Harris, C.; Hayes, G.; Kosmidis, C.; Denning, D.W. Twelve-month clinical outcomes of 206 patients with chronic pulmonary aspergillosis. PLOS ONE 2018, 13, e0193732. [CrossRef]

86. Felton, T.W.; Baxter, C.; Moore, C.B.; Roberts, S.A.; Hope, W.W.; Denning, D.W. Efficacy and Safety of Posaconazole for Chronic Pulmonary Aspergillosis. Clin. Infect. Dis. 2010, 51, 1383-1391. [CrossRef] [PubMed]

87. Agarwal, R.; Vishwanath, G.; Aggarwal, A.N.; Garg, M.; Gupta, D.; Chakrabarti, A. Itraconazole in chronic cavitary pulmonary aspergillosis: A randomised controlled trial and systematic review of literature. Mycoses 2013, 56, 559-570. [CrossRef] [PubMed]

88. Jain, L.R.; Denning, D.W. The efficacy and tolerability of voriconazole in the treatment of chronic cavitary pulmonary aspergillosis. J. Infect. 2006, 52, e133-e137. [CrossRef]

89. Boyd, A.E.; Modi, S.; Howard, S.J.; Moore, C.B.; Keevil, B.G.; Denning, D.W. Adverse Reactions to Voriconazole. Clin. Infect. Dis. 2004, 39, 1241-1244. [CrossRef]

90. Cadranel, J.; Philippe, B.; Hennequin, C.; Bergeron, A.; Bergot, E.; Bourdin, A.; Cottin, V.; Jeanfaivre, T.; Godet, C.; Pineau, M.; et al. Voriconazole for chronic pulmonary aspergillosis: A prospective multicenter trial. Eur. J. Clin. Microbiol. Infect. Dis. 2012, 31, 3231-3239. [CrossRef]

91. Skov, M.; Main, K.M.; Sillesen, I.B.; Mu, J. Iatrogenic adrenal insufficiency as a side-effect of combined treatment of itraconazole and budesonide. Eur. Respir. J. 2002, 20, 127-133. [CrossRef]

92. Dybro, A.M.; Damkier, P.; Rasmussen, T.B.; Hellfritzsch, M. Statin-associated rhabdomyolysis triggered by drug-drug interaction with itraconazole. BMJ Case Rep. 2016, 2016, bcr2016216457. [CrossRef]

93. Blondin, M.-C.; Beauregard, H.; Serri, O. Iatrogenic Cushing Syndrome in Patients Receiving Inhaled Budesonide and Itraconazole or Ritonavir: Two Cases and Literature Review. Endocr. Pract. 2013, 19, e138-e141. [CrossRef] [PubMed]

94. Kohno, S.; Izumikawa, K.; Ogawa, K.; Kurashima, A.; Okimoto, N.; Amitani, R.; Kakeya, H.; Niki, Y.; Miyazaki, Y. Intravenous micafungin versus voriconazole for chronic pulmonary aspergillosis: A multicenter trial in Japan. J. Infect. 2010, 61, 410-418. [CrossRef] [PubMed]

95. Newton, P.J.; Harris, C.; Morris, J.; Denning, D.W. Impact of liposomal amphotericin B therapy on chronic pulmonary aspergillosis. J. Infect. 2016, 73, 485-495. [CrossRef] [PubMed]

96. Kohno, S.; Masaoka, T.; Yamaguchi, H.; Mori, T.; Urabe, A.; Ito, A.; Niki, Y.; Ikemoto, H. A multicenter, open-label clinical study of micafungin (FK463) in the treatment of deep-seated mycosis in Japan. Scand. J. Infect. Dis. 2004, 36, 372-379. [CrossRef] [PubMed]

97. Kohno, S.; Izumikawa, K.; Kakeya, H.; Miyazaki, Y.; Ogawa, K.; Amitani, R.; Niki, Y.; Kurashima, A. Clinical efficacy and safety of micafungin in Japanese patients with chronic pulmonary aspergillosis: A prospective observational study. Med. Mycol. 2011, 49, 688-693. [CrossRef] 
98. Kohno, S.; Izumikawa, K.; Yoshida, M.; Takesue, Y. A double-blind comparative study of the safety and efficacy of caspofungin versus micafungin in the treatment of candidiasis and aspergillosis. Eur. J. Clin. Microbiol. Infect. Dis. 2013, 387-397. [CrossRef]

99. Brik, A.; Salem, A.M.; Kamal, A.R.; Abdel-Sadek, M.; Essa, M.; El Sharawy, M.; Deebes, A.; Bary, K.A. Surgical outcome of pulmonary aspergilloma. Eur. J. Cardiothorac. Surg. 2008, 34, 882-885. [CrossRef]

100. Muniappan, A.; Tapias, L.F.; Butala, P.; Wain, J.C.; Wright, C.D.; Donahue, D.M.; Gaissert, H.A.; Lanuti, M.; Mathisen, D.J. Surgical therapy of pulmonary aspergillomas: A 30-year North American experience. Ann. Thorac. Surg. 2014, 97, 432-438. [CrossRef]

101. Farid, S.; Mohamed, S.; Devbhandari, M.; Kneale, M.; Richardson, M.; Soon, S.Y.; Jones, M.T.; Krysiak, P.; Shah, R.; Denning, D.W.; et al. Results of surgery for chronic pulmonary Aspergillosis, optimal antifungal therapy and proposed high risk factors for recurrence-A National Centre's experience. J. Cardiothorac. Surg. 2013, 8, 180. [CrossRef]

102. Kosmidis, C.; Newton, P.; Muldoon, E.G.; Denning, D.W. Chronic fibrosing pulmonary aspergillosis: A cause of 'destroyed lung' syndrome. Infect. Dis. 2017, 49, 296-301. [CrossRef]

103. Kosmidis, C.; Powell, G.; Borrow, R.; Morris, J.; Alachkar, H.; Denning, D.W. Response to pneumococcal polysaccharide vaccination in patients with chronic and allergic aspergillosis. Vaccine 2015, 33, 7271-7275. [CrossRef] [PubMed]

104. Monk, E.J.M.; Harris, C.; Döffinger, R.; Hayes, G.; Denning, D.W.; Kosmidis, C. Interferon gamma replacement as salvage therapy in chronic pulmonary aspergillosis: Effects on frequency of acute exacerbation and all-cause hospital admission. Thorax 2020, 75, 513-516. [CrossRef] [PubMed]

105. Sambatakou, H.; Dupont, B.; Lode, H.; Denning, D.W. Voriconazole Treatment for Subacute Invasive and Chronic Pulmonary Aspergillosis. Am. J. Med. 2006, 119. [CrossRef] [PubMed]

106. Godet, C.; Laurent, F.; Bergeron, A.; Ingrand, P.; Beigelman-Aubry, C.; Camara, B.; Cottin, V.; Germaud, P.; Philippe, B.; Pison, C.; et al. CT Imaging Assessment of Response to Treatment in Chronic Pulmonary Aspergillosis. Chest 2016, 150, 139-147. [CrossRef]

107. Koyama, K.; Ohshima, N.; Suzuki, J.; Kawashima, M.; Takeda, K.; Ando, T.; Sato, R.; Nagai, H.; Matsui, H.; Ohta, K. Recurrence of chronic pulmonary aspergillosis after discontinuation of maintenance treatment by antifungal triazoles. J. Infect. Chemother. 2014, 20,375-379. [CrossRef]

108. Saraceno, J.L.; Phelps, D.T.; Ferro, T.J.; Futerfas, R.; Schwartz, D.B. Chronic Necrotizing Pulmonary Aspergillosis*: Approach to Management. Chest 1997, 112, 541-548. [CrossRef]

109. Denning, D.W. Chronic Aspergillosis. In Aspergillus Fumigatus and Aspergillosis; The American Society for Microbiology: Washington, DC, USA, 2009; pp. 319-331.

110. Naito, M.; Kurahara, Y.; Yoshida, S.; Ikegami, N.; Kobayashi, T.; Minomo, S.; Tachibana, K.; Tsuyuguchi, K.; Hayashi, S.; Suzuki, K. Prognosis of chronic pulmonary aspergillosis in patients with pulmonary non-tuberculous mycobacterial disease. Respir. Investig. 2018, 56, 326-331. [CrossRef]

111. Nam, H.S.; Jeon, K.; Um, S.W.; Suh, G.Y.; Chung, M.P.; Kim, H.; Kwon, O.J.; Koh, W.J. Clinical characteristics and treatment outcomes of chronic necrotizing pulmonary aspergillosis: A review of 43 cases. Int. J. Infect. Dis. 2010, 14, e479-e482. [CrossRef]

112. Chan, J.F.-W.; Lau, S.K.-P.; Wong, S.C.-Y.; To, K.K.-W.; So, S.Y.-C.; Leung, S.S.-M.; Chan, S.-M.; Pang, C.-M.; Xiao, C.; Hung, I.F.-N.; et al. A 10-year study reveals clinical and laboratory evidence for the 'semi-invasive' properties of chronic pulmonary aspergillosis. Emerg. Microbes. Infect. 2016, 5, e37. [CrossRef]

113. Iqbal, N.; Irfan, M.; Zubairi, A.B.S.; Jabeen, K.; Awan, S.; Khan, J.A. Clinical manifestations and outcomes of pulmonary aspergillosis: Experience from pakistan. BMJ Open. Respir. Res. 2016, 3. [CrossRef]

114. Jakribettu, R.P.; George, T.; Abraham, S.; Fazal, F.; Kinila, S.; Baliga, M.S. Clinical and laboratory profile of chronic pulmonary aspergillosis: A retrospective study. Egypt. J. Bronchol. 2019, 13, 109. [CrossRef]

(C) 2020 by the authors. Licensee MDPI, Basel, Switzerland. This article is an open access article distributed under the terms and conditions of the Creative Commons Attribution (CC BY) license (http://creativecommons.org/licenses/by/4.0/). 